\title{
Medication-induced Uveitis: An Update
}

\author{
Kashif M Iqbal, BS ${ }^{1}$; Madeline W Hay, BS ${ }^{2}$; Parisa Emami-Naeini, MD, MPH \\ (KM lqbal and MW Hay contributed equally to this paper.) \\ ${ }^{1}$ University of California Riverside School of Medicine, Riverside, CA \\ ${ }^{2}$ Western University of Health Sciences, Pomona, CA \\ ${ }^{3}$ Department of Ophthalmology and Vision Science, University of California, Davis, Sacramento, CA, USA \\ ORCID: \\ Parisa Emami-Naeini: https://orcid.org/0000-0002-4494-7517
}

\section{Abstract}

Drug-induced uveitis is an uncommon but important cause of ocular inflammation. Uveitis can be seen in association with various systemic, topical, and intraocular medications. In this article, we review common medications associated with uveitis. Most cases of drug-induced uveitis resolve with termination of the suspected medication with or without administration of topical or systemic steroids. It is important for clinicians to readily identify medications that may cause uveitis in order to provide rapid treatment, avoid consequences of longstanding inflammation, and prevent costly and excessive laboratory testing.

Keywords: Uveitis; Medication; Medication-induced Uveitis

J Ophthalmic Vis Res 2021; 16 (1): 84-92

\section{INTRODUCTION}

Uveitis is generally defined as inflammation in the uveal tract, which is composed of the iris, ciliary body, and choroid. Uveitis most commonly affects young, working-age adults, and it has been reported to be responsible for $5-20 \%$ of all cases of blindness in the United States and worldwide. ${ }^{[1,2]}$ According to the International Uveitis Study Group, uveitis is classified based on anatomic location of involvement, and can manifest as anterior, intermediate, posterior, and panuveitis. ${ }^{[3-5]}$ It can also be classified based on

\section{Correspondence to:}

Parisa Emami-Naeini, MD, MPH. Department of Ophthalmology and Vision Science, University of California, 4860 Y St., Suite 2400, Sacramento, CA 95817, USA.

E-mail: Parisaemami@gmail.com

Received: 13-06-2020 Accepted: 04-12-2020

\section{Access this article online}

Website: https://knepublishing.com/index.php/JOVR

DOI: 10.18502/jovr.v16i1.8254 etiology, including infectious, non-infectious, and masquerade syndromes. ${ }^{[3]}$

Medications are a rare cause of uveitis, comprising $<0.5 \%$ of cases. $^{[1,6]}$ Drug-induced uveitis, although uncommon, can sometimes cause severe inflammation and is easily misdiagnosed. Hence, a high degree of suspicion is required to establish the diagnosis. Several criteria have been proposed to describe the causality of adverse events from medications, including a reaction that is frequently described and documented, recovery upon drug withdrawal, more severe reaction with higher doses, and recurrence with drug rechallenge; rarely does a drug meet all of these criteria. ${ }^{[7]}$ The pathogenesis of drug-induced uveitis is not fully understood, but various mechanisms have been proposed

This is an open access journal, and articles are distributed under the terms of the Creative Commons Attribution-NonCommercial-ShareAlike 4.0 License, which allows others to remix, tweak, and build upon the work non-commercially, as long as appropriate credit is given and the new creations are licensed under the identical terms.

How to cite this article: Iqbal KM, Hay MW, Emami-Naeini P. Medicationinduced Uveitis: An Update. J Ophthalmic Vis Res 2021;16:84-92. 
including a direct effect from topical application or intracameral injection, metabolite effects from drug detoxification, type III hypersensitivity reaction with immune complex deposition of antidrug antibodies, and antigens liberated from drug-induced death of microorganisms. ${ }^{[8]}$ Medications may also be broken down into free radicals that bind melanin in the uveal tract, which can cause toxicity and reduce melanin's ability to scavenge other free radicals, causing uveitis. ${ }^{[8,9]}$

In the current article, we review common systemic, topical, intracameral, and intravitreal medications associated with uveitis. New medications linked to uveitis that have been reported in the literature will also be highlighted.

\section{TOPICAL MEDICATIONS}

\section{Brimonidine}

Brimonidine is an alpha-2 adrenergic agonist that is administered topically to reduce intraocular pressure. Acute granulomatous or non-granulomatous anterior uveitis with an elevated intraocular pressure has been reported with brimonidine use. ${ }^{[10,11]}$ The mechanism by which this inflammatory response occurs is largely unknown, but there is a higher risk in patients with history of allergic conjunctivitis from brimonidine use and in patients using drops for $>12$ months. ${ }^{[12]}$ Stopping the medicine usually resolves the inflammation and rechallenge results in recurrence of uveitis. ${ }^{[11]}$

\section{Prostaglandin analogues}

Topical prostaglandin analogs increase uveoscleral outflow of aqueous humor, and are used in the treatment of glaucoma. ${ }^{[13]}$ Latanoprost is associated with a $5 \%$ risk of anterior uveitis within the first several months of treatment. ${ }^{[14,15]}$ A significant increase in anterior chamber cell and flare has been reported at three and six months after the initiation of latanoprost, travoprost, and bimatoprost. ${ }^{[16]}$ This may be due to breakdown of the blood-aqueous barrier and subsequent elevation of cytokines in the anterior chamber. ${ }^{[16,17]}$ Use of these drops has also been associated with the development of cystoid macular edema. ${ }^{[15]}$

\section{INTRAOCULAR INJECTIONS}

\section{Vancomycin}

Intracameral vancomycin is used for prevention of endophthalmitis following cataract surgery. ${ }^{[18]}$ However, vancomycin use has been associated with hemorrhagic occlusive retinal vasculitis (HORV), often presenting with anterior chamber and vitreous inflammation as well as painless vision loss. $^{[18]}$ All reported cases of HORV presented within 1-21 days (mean 8 days) after vancomycin use. These patients received vancomycin via intracameral injection, intravitreal injection, or through the irrigation bottle. Retinal vasculitis in most of these patients resulted in poor visual outcomes. ${ }^{[18]}$ The proposed mechanism by which this reaction occurs is via a delayed immune response to the drug itself. ${ }^{[18]}$

Anti-vascular endothelial growth factor (antiVEGF) agents

Anti-vascular endothelial growth factors (antiVEGFs) such as bevacizumab (Avastin ${ }^{\circledR}$ ), ranibizumab (Lucentis ${ }^{\circledR}$ ), and aflibercept (Eylea ${ }^{\circledR}$ ) are commonly used in the treatment of neovascular age-related macular degeneration, macular edema secondary to diabetic retinopathy and vascular occlusion, and proliferative retinopathies. After two years of anti-VEGF therapy, there is a two-fold increase in the prevalence of uveitis compared to disease-matched controls. ${ }^{[19]}$

Intraocular inflammation has been the dose-limiting variable for intravitreal use of ranibizumab. ${ }^{[20]}$ During the FOCUS trial, a $12 \%$ rate of uveitis was found following ranibizumab injection; however, the majority of these cases occurred prior to switching from the lyophilized formulation (no longer in use) to the liquid formulation, as well as prolonging the interval between injection and verteporfin photodynamic therapy. ${ }^{[21]}$ These changes were made to the protocol due to concerns that these factors increased the risk of uveitis. ${ }^{[21]} \mathrm{ANCHOR}$ and MARINA clinical trials estimated that approximately $2 \%$ of patients receiving intravitreal injections of ranibizumab developed significant inflammation (classified as $3+$ or more cell in the anterior chamber) within three weeks of injection. ${ }^{[21,22]}$ The HORIZON extension study evaluated the long-term safety of ranibizumab in patients 
who had completed the ANCHOR, MARINA, or FOCUS trials, and found that significant intraocular inflammation presented in 1.7$2.6 \%$ of the eyes receiving ranibizumab for one to three years. ${ }^{[23]}$ Another study reported that both bevacizumab and aflibercept were associated with a $<1 \%$ risk of significant intraocular inflammation. ${ }^{[24]}$

The newest drug in the anti-VEGF family is Brolucizumab $\left(\right.$ Beovu $\left.^{\circledR}\right)$, which comprises a humanized single-chain antibody fragment with a molecular weight of $26 \mathrm{kDa}$, and recently received FDA approval for use in patients with wet agerelated macular degeneration. ${ }^{[25]}$ The efficacy and safety of brolucizumab was evaluated and compared with aflibercept in the HAWK and HARRIER phase-three multicenter randomized trials, which found that uveitis was present in $2.2 \%$ and $0 \%$ of patients taking brolucizumab and aflibercept, respectively. ${ }^{[25]}$ About $90 \%$ of these cases were mild to moderate, and were treated successfully with topical corticosteroids. ${ }^{[25]}$ In the post-hoc analysis of the HAWK and HARRIER data, Mones et $\mathrm{al}^{[26]}$ reported that the incidence of intraocular inflammation was $4.6 \%$ in eyes treated with brolucizumab; $3.3 \%$ of patients developed retinal vasculitis with occlusive vasculitis in $2.1 \%$ of the eyes. ${ }^{[26]}$ In addition, $0.7 \%$ of the cases experienced at least moderate vision loss ( $\geq 15$ ETDRS letters), and most of these events occurred in the first six months of drug use. In the same study, the incidence of intraocular inflammation in aflibercept-treated eyes was $1.1 \%$, with at least moderate vision loss in $0.14 \% .{ }^{[26]}$ The mechanism for intraocular inflammation secondary to anti-VEGF injections is not fully understood, but some experts suggest that it is due to the formation of anti-drug antibodies and subsequent hypersensitivity reactions to the medicine. ${ }^{[27]}$

\section{Triamcinolone acetonide}

Intravitreal injection of triamcinolone acetonide, used in the treatment of non-infectious uveitis and macular edema, has been associated with sterile inflammation and non-infectious endophthalmitis. The reported incidence is between $0.5 \%$ and $9.7 \%$ of injections, and significantly increases with the use of preservatives. ${ }^{[14]}$

\section{SYSTEMIC MEDICATIONS}

\section{Cidofovir}

Cidofovir is a nucleotide analog that inhibits viral DNA polymerase and is used for the treatment of infection with herpesviruses such as cytomegalovirus (CMV). ${ }^{[28]}$ Uveitis has been reported in $25-50 \%$ of patients after a median of 11 weekly doses of intravenous cidofovir. ${ }^{\text {[29-32] }}$ Uveitis is more common after intravitreal use of cidofovir. ${ }^{[31]}$ HIV patients who receive cidofovir for CMV retinitis are at higher risk of uveitis. In these patients, treatment with highly active anti-retroviral therapy (HAART) is an independent risk factor, likely secondary to higher circulating levels of cidofovir in setting of HAART. ${ }^{[33]}$ Moreover, it has been suggested that an elevated level of CD4+ T-cells in HIV+ patients is a risk factor for cidofovir uveitis, which makes it difficult to differentiate from immune recovery uveitis. ${ }^{[33,34]}$ Concurrent use of probenecid, on the other hand, can significantly decrease the rate of ocular side effects as it minimizes intraocular secretion of cidofovir. ${ }^{[35]}$ Cidofovir-induced hypotony is seen in $10-20 \%$ of $\mathrm{HIV}+$ patients treated for CMV retinitis. ${ }^{[31,32]}$ The inflammation and hypotony usually respond to treatment with topical steroids and cycloplegic agents, but hypotony can persist for a long period of time. ${ }^{[30,35,36]}$

\section{Rifabutin}

Rifabutin, used for prevention and treatment of Mycobacterium avium complex (MAC) in immunocompromised patients, can cause unilateral or bilateral anterior uveitis (usually associated with hypopyon), intermediate uveitis, posterior uveitis, or retinal vasculitis. ${ }^{[14,37]}$ Uveitis is usually dose-dependent and commonly occurs between two weeks and seven months following the initiation of therapy. ${ }^{[38]}$ Serum concentration and hence risk of inflammation increases with concurrent use of antifungal azoles, azithromycin, ethambutol, and some protease inhibitors through inhibition of hepatic cytochrome P450 enzymes. ${ }^{[28,37]}$ Notably, rifabutin-induced uveitis has also been reported in children and immunocompetent patients. ${ }^{[28]}$ Inflammation usually resolves with topical steroids. ${ }^{[28]}$ 


\section{Fluoroquinolones}

Fluoroquinolones, which disrupt bacterial DNA synthesis by inhibiting DNA gyrase and DNA topoisomerase IV, have a broad spectrum of antibacterial activity indicated for the treatment of community-acquired pneumonia, sinusitis, chronic bronchitis, intra-abdominal abscesses, and skin infections. ${ }^{[39,40]}$ In Hinkle et al's retrospective analysis of 40 case reports of fluoroquinoloneinduced uveitis, moxifloxacin was associated with 25 cases, but ofloxacin, ciprofloxacin, levofloxacin, norfloxacin, and gatifloxacin have also been reported to cause uveitis. ${ }^{[1,28,40,41]}$ The mean onset of uveitis is 13 days after the initiation of the drug (range: 0-20 days) and is usually bilateral; three characteristic findings in these patients include pigment dispersion with pigmented keratic precipitates and high intraocular pressure, diffuse iris transilluminating defects, and atonic pupils. ${ }^{[40-42]}$ Fluoroquinoloneinduced uveitis is more common in women and has been associated with HLA-B27 and HLA-B51 haplotypes, suggesting a possible autoimmune predisposition. ${ }^{[40]}$ Uveitis is treated by discontinuing the drug and administration of topical corticosteroids. ${ }^{[41]}$

\section{Bisphosphonates}

Bisphosphonates, pyrophosphate analogs that inhibit osteoclast activity, are commonly used to inhibit bone resorption in osteoporosis and metastasis to bone. ${ }^{[28]}$ They are strongly associated with anterior uveitis, scleritis, and episcleritis, with onset as early as $6 \mathrm{hr}$ after intravenous administration. ${ }^{[1,43,44]}$ In a large retrospective pharmacovigilance study, zoledronate caused $51 \%$ of bisphosphonateinduced uveitis, with alendronate and pamidronate causing $23 \%$ and $13 \%$, respectively. ${ }^{[1]}$ The bisphosphonates promote the release of inflammatory cytokines such as interleukin 1, interleukin 6, and tumor necrosis factor (TNF)- $\alpha$, which can target the uveal tract. ${ }^{[45]}$ Resolution typically requires topical steroids and discontinuation of the medicine. ${ }^{[28]}$

\section{TNF- $\alpha$ Inhibitors}

TNF- $\alpha$ inhibitors are a group of anti-inflammatory biologics that are used for the treatment of rheumatologic diseases such as rheumatoid arthritis, psoriasis, and inflammatory bowel disease, as well as scleritis and uveitis. ${ }^{[41]}$ Five anti-TNF- $\alpha$ drugs are currently approved for the use in autoimmune diseases, including four monoclonal antibodies (infliximab, adalimumab, golimumab, and certolizumab) and a soluble receptor blocker (etanercept). ${ }^{[4]}$ All of these medications have been paradoxically associated with the development of anterior uveitis and chorioretinitis. Inflammation is more common with etanercept but has also been reported with infliximab and adalimumab. ${ }^{[4]}$ The onset of uveitis is usually three weeks to six years after starting the therapy. ${ }^{[41,47,48]}$ Sarcoidosis has also been reported in patients using etanercept. ${ }^{[46]}$ The etiology of anti-TNF- $\alpha$-induced uveitis is not fully understood, but it is hypothesized that decreased TNF- $\alpha$ levels leads to higher interferon levels and cytokine imbalances, resulting in autoantibody formation and increased inflammation. ${ }^{[49]}$ Treatment involves discontinuation of the drug, with severe cases requiring systemic steroids ${ }^{[41]}$ [Figure 1].

\section{Immune Checkpoint Inhibitors}

Immune Checkpoint Inhibitors (ICls) are emerging cancer immunotherapies used in metastatic melanoma and solid tumors. ${ }^{[1]}$ They upregulate the immune system by blocking immune checkpoints that are regulators of immune system, thus leading to activation of T-cells and an immune response to tumor cells. ${ }^{[50,51]}$ The different types of ICls approved for use in cancer patients include a CTLA-4 inhibitor (ipilimumab), programmed cell death protein 1 (PD-1) inhibitors (pembrolizumab, nivolumab, and cemiplimab), and PD-1 ligand inhibitors (atezolizumab, avelumab, and durvalumab). ${ }^{[14,52]}$ These medications have recently been linked to ocular inflammation. Uveitis is seen in $1 \%$ of patients and is usually bilateral with onset between one and six months after the initiation of treatment. ${ }^{[14,51,53,54]}$ There are also reports of Vogt-Koyanagi-Harada (VKH) syndrome in patients receiving ICls. ${ }^{[1]}$ Ocular inflammation in these patients is managed with topical or periocular steroids, but severe cases require systemic steroids and discontinuation of $\mathrm{ICls}^{[51]}$ [Figure 2]. 


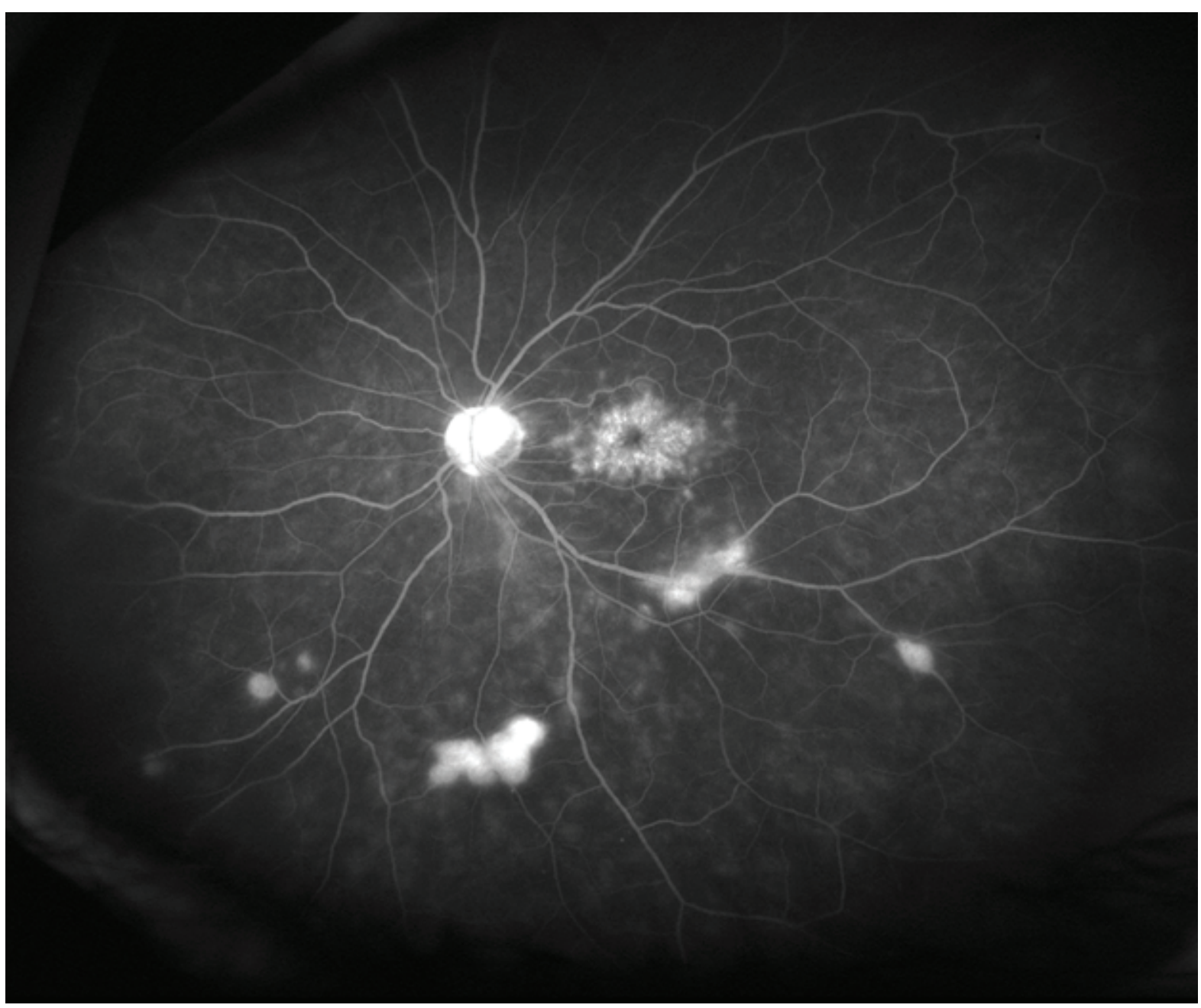

Figure 1. Fluorescein angiography of a 67-year-old female with history of rheumatoid arthritis treated with etanercept who developed uveitis and retinal vasculitis three months after the initiation of etanercept. Etanercept was discontinued and infliximab was started which resulted in resolution of ocular inflammation.

\section{Protein Kinase Inhibitors}

Dysregulations in mitogen-activated protein kinase (MAPK) signaling pathways and BRAF gene mutations, seen in $50 \%$ of skin melanoma patients, can cause cell proliferation and cancer formation. ${ }^{[14]}$ BRAF inhibitors, such as vemurafenib and dabrafenib, and mitogen-activated protein kinases (MEK) inhibitors, such as trametinib, are new drugs of interest in the treatment of metastatic cutaneous melanomas. These medications have recently been linked to ocular inflammation. ${ }^{[1]}$ Uveitis usually occurs between six weeks and eight months after the initiation of treatment, and can present as anterior, intermediate, posterior, or panuveitis; resolution typically involves topical steroids. ${ }^{[14]}$ There are also reports of drug-induced VKH syndrome linked to the combination treatment with dabrafenibtrametinib. ${ }^{[1]}$

\section{MISCELLANEOUS}

\section{Vaccines}

There are reports of uveitis in association with BCG, influenza, hepatitis $B$, varicella, and human papilloma virus vaccines. ${ }^{[14]}$ Most of these cases respond to topical steroid treatment or observation and permanent vision loss is rare. ${ }^{[14]}$

\section{Other medications}

Sulfonamides, including antibiotics (most commonly trimethoprim-sulfamethoxazole), diuretics, and sulfonylureas, have been associated 

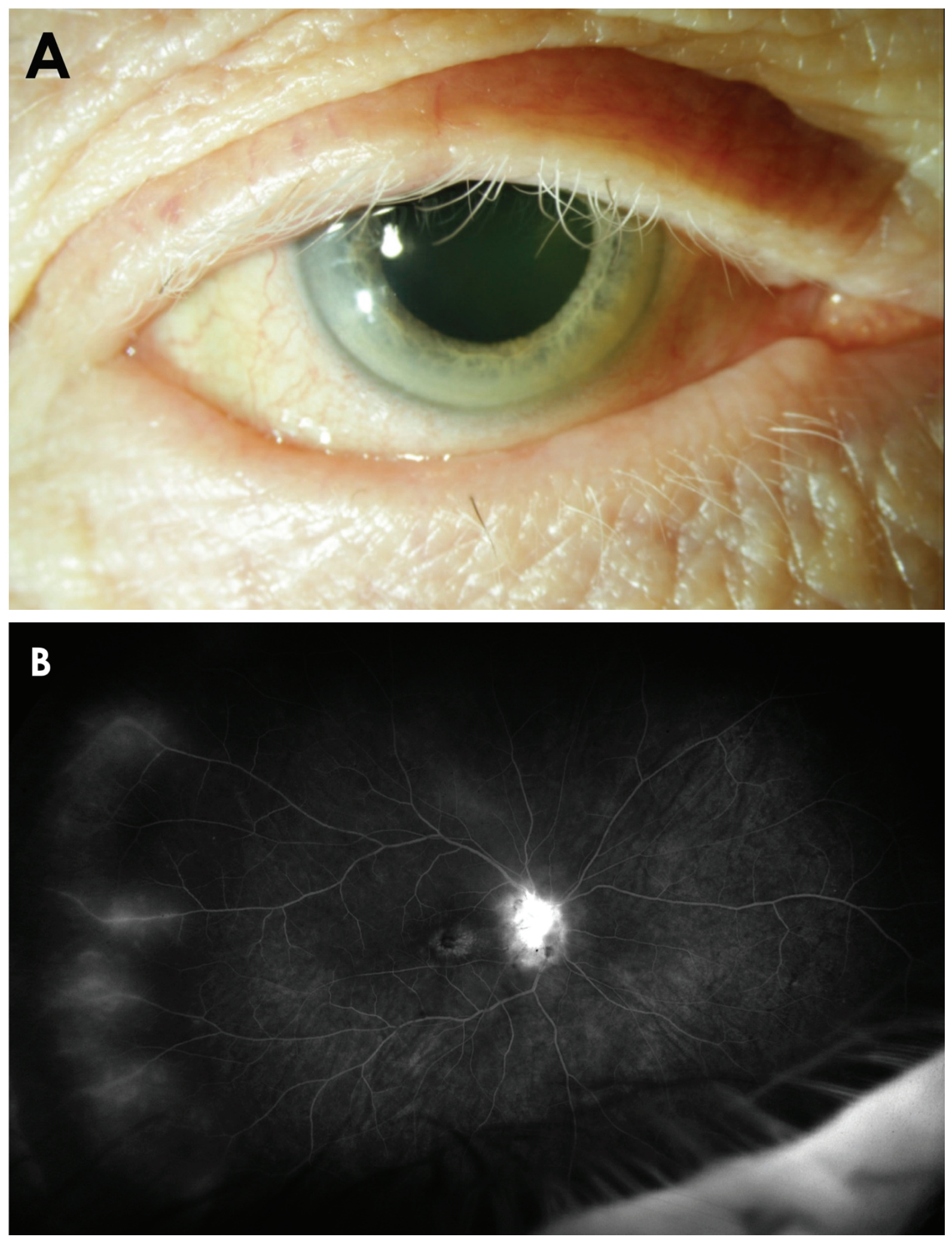

Figure 2. (A) 77-year-old man with history of malignant skin melanoma treated with nivolumab presented with blurry vision in both eyes. External exam showed poliosis of the eyelashes. Ultrawide field fluorescein angiography showed optic nerve and vascular leakage $(B)$ which improved after intravitreal injection of triamcinolone acetonide. 


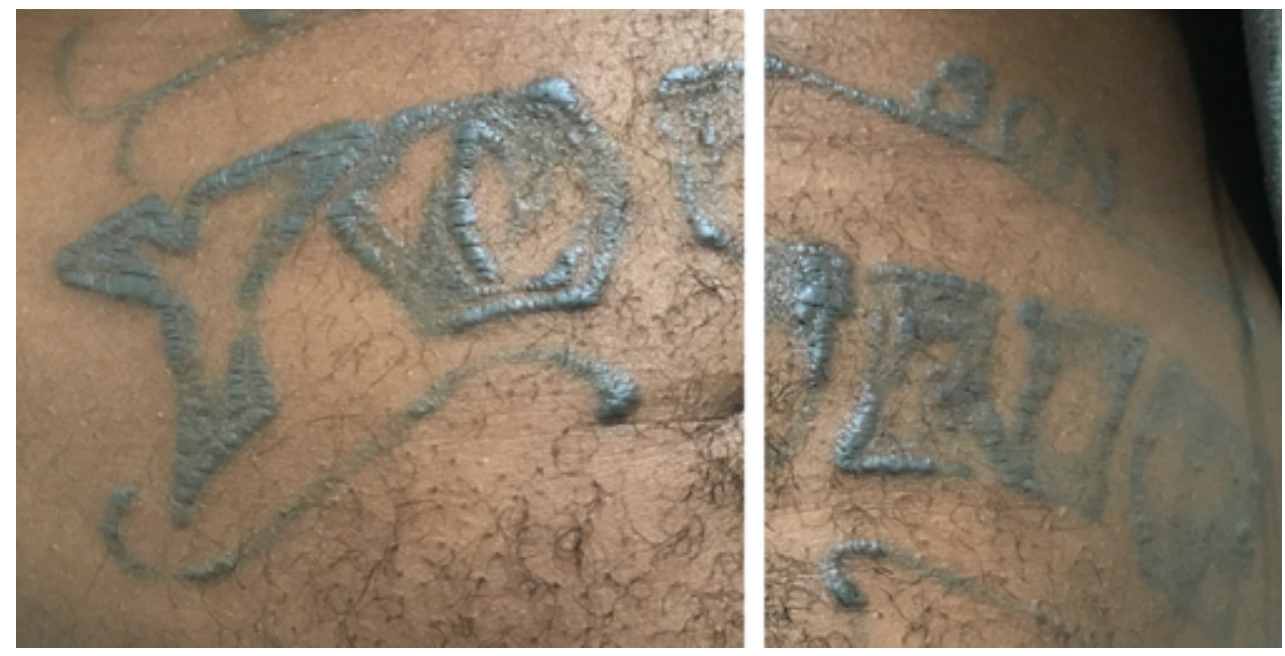

Figure 3. Inflamed, indurated skin tattoos in a young patient with tattoo uveitis.

with bilateral anterior uveitis usually within a week of drug initiation. ${ }^{28,41,55]}$ Topical metipranolol, a nonselective $\beta$-blocker used to treat glaucoma, has been linked to granulomatous anterior uveitis most commonly when used at a higher concentration of $0.6 \%{ }^{[28,56]}$ Onset ranged from 2 to 31 months, and strong dechallenge and rechallenge data have also been reported. ${ }^{[41,56]}$ Other medications that can rarely cause uveitis include podophyllum, capsaicin, betaxolol, oral contraceptives, diethylcarbamazine, corticosteroids, quinidine, topiramate, and tuberculin skin tests. ${ }^{[6,8,14,28]}$ Almost all of these cases resolved with cessation of the medication and initiation of topical steroids. ${ }^{[6,14,28]}$

\section{Tattoo ink}

There are multiple reports of patients with simultaneous bilateral uveitis and elevated inflamed skin tattoos. Skin biopsies from the indurated tattoos in these patients revealed granulomatous inflammation surrounding tattoo pigments, and some patients developed noncaseating granulomas in the draining lymph nodes corresponding to the location of the tattoos. ${ }^{[57]}$ An association between systemic sarcoidosis and tattoo uveitis has been reported by some authors, but uveitis can be found with or without a sarcoidosis diagnosis. ${ }^{[57,58]}$ Inflammation is more commonly seen in association with black ink, and there are reports of resolution of uveitis after removal of the skin tattoos. ${ }^{[58]}$ The etiology has not been clearly defined, but a type IV delayed hypersensitivity reaction has been proposed ${ }^{[58]}$ [Figure 3].

\section{CONCLUSION}

Drug-induced uveitis is seen in association with a growing list of various topical, intraocular, and systemic medications. Although uncommon, medication-induced uveitis can cause severe, vision-threatening inflammation, and will increase in frequency with the development of new medications. The diagnosis is often made by a thorough history and evaluation of medication list, and after ruling out other potential infectious or non-infectious etiologies of ocular inflammation. Early identification of uveitis and rapid treatment can lead to decreased morbidity and complications of longstanding uveal inflammation, thus improving visual outcomes. Most of these cases respond to cessation of the insulting agent in conjunction with topical and/or systemic corticosteroids. ${ }^{[14]}$

\section{Financial Support and Sponsorship}

None.

\section{Conflicts of Interest}

There are no conflicts of interest.

\section{REFERENCES}

1. Anquetil C, Salem JE, Lebrun-Vignes B, Touhami S, Desbois AC, Maalouf G, et al. Evolving spectrum of druginduced uveitis at the era of immune checkpoint inhibitors 
results from the WHO's pharmacovigilance database. $J$ Autoimmun 2020;102454

2. McCannel C, Holland G, Helm C, Cornell P, Winston J, Rimmer T. Causes of uveitis in the general practice of ophthalmology. Am J Ophthalmol 1996;121:35-46.

3. Deschenes J, Murray PI, Rao NA, Nussenblatt RB. International Uveitis Study Group (IUSG) clinical classification of uveitis. Ocul Immunol Inflamm 2008;16:12.

4. Bloch-Michel E, Nussenblatt RB. International Uveitis Study Group recommendations for the evaluation of intraocular inflammatory disease. Am J Ophthalmol 1987;103:234-235.

5. Jabs DA, Nussenblatt RB, Rosenbaum JT. Standardization of Uveitis Nomenclature (SUN) Working Group. Standardization of uveitis nomenclature for reporting clinical data. Results of the First International Workshop. Am J Ophthalmol 2005;140:509-516.

6. Jabs DA, Nussenblatt RB, Rosenbaum JT, Standardization of Uveitis Nomenclature (SUN) Working Group. Standardization of uveitis nomenclature for reporting clinical data. Results of the First International Workshop. Am J Ophthalmol 2005;140:509-516.

7. A method for estimating the probability of adverse drug reactions. Clin Pharmacol Ther 1981;30:239-245.

8. Moorthy R, Valluri S, Jampol L. Drug-induced uveitis. Surv Ophthalmol 1998;42:557-570.

9. Cordero-Coma M, Salazar-Méndez R, Garzo-García I, Yilmaz T. Drug-induced uveitis. Expert Opin Drug Saf 2015;14:111-126.

10. Byles DB, Frith P, Salmon JF. Anterior uveitis as a side effect of topical brimonidine. Am J Ophthalmol 2000;130(3):287-291.

11. Becker HI, Walton RC, Diamant JI, Zegans ME. Anterior uveitis and concurrent allergic conjunctivitis associated with long-term use of topical $0.1 \%$ brimonidine tartrate. Arch Ophthalmol 2004;122:1063-1066.

12. Sharma A, Kumar N, Kuppermann BD, Francesco B, Loewenstein A. Biotherapeutics and immunogenicity: ophthalmic perspective. Eye 2019;33:1359-1361.

13. Winkler NS, Fautsch MP. Effects of prostaglandin analogues on aqueous humor outflow pathways. J Ocul Pharmacol Th 2014;30:102-109.

14. Moorthy RS, Moorthy MS, Cunningham, ET Jr. Druginduced uveitis. Curr Opin Ophthalmol 2018;29:588-603.

15. Warwar RE, Bullock JD, Ballal D. Cystoid macular edema and anterior uveitis associated with latanoprost use: experience and incidence in a retrospective review of 94 patients. Ophthalmology 1998;105:263-268.

16. Cellini M, Caramazza R, Bonsanto D, Bernabini B, Campos E. Prostaglandin analogs and blood-aqueous barrier integrity: a flare cell meter study. Ophthalmologica 2004;218:312-317.

17. Park H-YL, Kim JH, Lee KM, Park CK. Effect of prostaglandin analogues on tear proteomics and expression of cytokines and matrix metalloproteinases in the conjunctiva and cornea. Exp Eye Res 2012;94:13-21.

18. Witkin AJ, Chang DF, Jumper JM, Charles S, Eliott D, Hoffman RS, et al. Vancomycin-associated hemorrhagic occlusive retinal vasculitis: clinical characteristics of 36 eyes. Ophthalmology 2017;124(5):583-595.
19. Day S, Acquah K, Mruthyunjaya P, Grossman DS, Lee PP, Sloan FA. Ocular complications after anti-vascular endothelial growth factor therapy in medicare patients with age-related macular degeneration. Am J Ophthalmol 2011:152:266-272.

20. Rosenfeld PJ, Moshfeghi AA, Puliafito CA. Optical coherence tomography findings after an intravitreal injection of bevacizumab (Avastin ${ }^{\circledR}$ ) for neovascular agerelated macular degeneration. OSLI Retina 2005;36:331335.

21. Antoszyk AN, Tuomi L, Chung CY, Singh A, Group FS. Ranibizumab combined with verteporfin photodynamic therapy in neovascular age-related macular degeneration (FOCUS): year 2 results. Am J Ophthalmo/ 2008;145:862874.

22. Brown DM, Michels M, Kaiser PK, Heier JS, Sy JP, lanchulev $\mathrm{T}$, et al. Ranibizumab versus verteporfin photodynamic therapy for neovascular age-related macular degeneration: two-year results of the ANCHOR study. Ophthalmology 2009;116:57-65.

23. Singer MA, Awh CC, Sadda S, Freeman WR, Antoszyk AN, Wong P, et al. HORIZON: an open-label extension trial of ranibizumab for choroidal neovascularization secondary to age-related macular degeneration. Ophthalmology 2012;119(6):1175-1183.

24. Wells JA, Glassman AR, Ayala AR, Jampol LM, Bressler $\mathrm{NM}$, Bressler SB, et al. Aflibercept, bevacizumab, or ranibizumab for diabetic macular edema: two-year results from a comparative effectiveness randomized clinical trial. Ophthalmology 2016;123(6):1351-1359.

25. Dugel PU, Koh A, Ogura Y, Jaffe GJ, Schmidt-Erfurth $\mathrm{U}$, Brown DM, et al. HAWK and HARRIER: phase 3, multicenter, randomized, double-masked trials of brolucizumab for neovascular age-related macular degeneration. Ophthalmology 2020;127(1):72-84.

26. Mones J, Srivastava S, Jaffe G, Tadayoni R, Albini TA, Kaiser PK, et al. Risk of inflammation, retinal vasculitis and retinal occlusion-related events with brolucizumab: posthoc review of HAWK and HARRIER. Ophthalmology 2020.

27. Sharma A, Kumar N, Parachuri N, Sharma R, Bandello F, Kuppermann BD, et al. Brolucizumab and immunogenicity. Eye 2020:1-3.

28. Shifera AS, Kopplin L, Lin P, Suhler EB. Drug-induced uveitis. Int Ophthal Clin 2015;55:47-65.

29. Kirsch LS, Arevalo JF, Chavez de la Paz E, Munguia D, De Clercq E, Freeman WR. Intravitreal cidofovir (HPMPC) treatment of cytomegalovirus retinitis in patients with acquired immune deficiency syndrome. Ophthalmology 1995;102:533-542.

30. Chavez-de la Paz E, Arevalo JF, Kirsch LS, Munguia D, Rahhal FM, De Clercq E, et al. Anterior nongranulomatous uveitis after intravitreal HPMPC (cidofovir) for the treatment of cytomegalovirus retinitis. Analysis and prevention. Ophthalmology 1997;104:539-544.

31. Davis JL, Taskintuna I, Freeman WR, Weinberg DV, Feuer WJ, Leonard RE. Iritis and hypotony after treatment with intravenous cidofovir for cytomegalovirus retinitis. Arch Ophthalmol 1997;115:733-737.

32. Ambati J, Wynne KB, Angerame MC, Robinson MR. Anterior uveitis associated with intravenous cidofovir use in patients with cytomegalovirus retinitis. Br J Ophthalmol 1999;83:1153-1158. 
33. Cunningham ET. Uveitis in HIV positive patients. $\mathrm{Br} \mathrm{J}$ Ophthalmol 2000;84:233-236.

34. Robinson MR, Reed G, Csaky KG, Polis MA, Whitcup SM. Immune-recovery uveitis in patients with cytomegalovirus retinitis taking highly active antiretroviral therapy. Am J Ophthalmol 2000;130:49-56.

35. London NJ, Garg SJ, Moorthy RS, Cunningham ET. Druginduced uveitis. J Ophthal Inflamm Infect 2013;3:43.

36. Bainbridge JW, Raina J, Shah SM, Pinching AJ. Ocular complications of intravenous cidofovir for cytomegalovirus retinitis in patients with AIDS. Eye 1999;13:353-356.

37. Nichols CW. Mycobacterium avium complex infection, rifabutin, and uveitis-is there a connection? Clin Infect Dis 1996;22:43-47.

38. Shafran SD, Singer J, Zarowny DP, Deschenes J, Phillips $\mathrm{P}$, Turgeon $\mathrm{F}$, et al. Determinants of rifabutinassociated uveitis in patients treated with rifabutin, clarithromycin, and ethambutol for Mycobacterium avium complex bacteremia: a multivariate analysis. J Infect Dis 1998;177:252-255.

39. Drlica K, Zhao X. DNA gyrase, topoisomerase IV, and the 4-quinolones. Microbiol Mol Biol Rev 1997;61:377-392.

40. Hinkle DM, Dacey MS, Mandelcorn E, Kalyani P, Mauro $\mathrm{J}$, Bates $\mathrm{JH}$, et al. Bilateral uveitis associated with fluoroquinolone therapy. Cutan Ocul Toxicol 2012;31:111116.

41. Moorthy RS, London NJS, Garg SJ, Cunningham, ET, Jr. Drug-induced uveitis. Curr Opin Ophthalmol 2013;24:589-597.

42. Bettink-Remeijer MW, Brouwers K, Langenhove LV, De Waard PWT, Missotten TO, Martinez JP, et al. Uveitis-like syndrome and iris transillumination after the use of oral moxifloxacin. Eye 2009;23:2260-2262.

43. Fraunfelder FW, Fraunfelder FT. Bisphosphonates and ocular inflammation. N Engl J Med 2003;348:1187-1188.

44. Fraunfelder FW, Fraunfelder FT, Jensvold B. Scleritis and other ocular side effects associated with pamidronate disodium. Am J Ophthal 2003;135:219-222.

45. Fietta P, Manganelli P, Lodigiani L. Clodronate-induced uveitis. Ann Rheum Dis 2003;62:378.
46. Majjad A, Bezza A, Biyi A, El Ochi MR, El Maghraoui A. Pulmonary sarcoidosis following etanercept treatment for ankylosing spondylitis: a case report and review of the literature. Case Rep Rheumatol 2018;9867248.

47. Lim LL, Fraunfelder FW, Rosenbaum JT. Do tumor necrosis factor inhibitors cause uveitis? A registry-based study. Arthritis Rheum 2007;56:3248-3252.

48. Fonollosa A, Artaraz J, Les I, Martinez-Berriotoxoa A, Izquierdo JP, Lopez AS, et al. Sarcoid intermediate uveitis following etanercept treatment: a case report and review of the literature. Ocul Immunol Inflamm 2012;20:44-48.

49. Cunningham ET Jr, Pasadhika S, Suhler EB, Zierhut $M$. Drug-induced inflammation in patients on TNFalpha inhibitors. Ocul Immunol Inflamm 2012;20:2-5.

50. Pardoll DM. The blockade of immune checkpoints in cancer immunotherapy. Nat Rev Cancer 2012;12:252264.

51. Dalvin LA, Shields CL, Orloff $M$, Sato T, Shields JA. Checkpoint inhibitor immune therapy: systemic indications and ophthalmic side effects. Retina 2018;38:1063-1078.

52. Cunningham ET, Moorthy RS, Zierhut M. Immune checkpoint inhibitor-induced uveitis. Ocul Immunol Inflamm 2020;28:847-849.

53. Robert C, Schachter J, Long GV, Arance A, Grob JJ, Mortier $\mathrm{L}$, et al. Pembrolizumab versus ipilimumab in advanced melanoma. N Engl J Med 2015I;372:2521-2532.

54. Antonia SJ, López-Martin JA, Bendell J, Ott PA, Taylor $\mathrm{M}$, Eder JP, et al. Nivolumab alone and nivolumab plus ipilimumab in recurrent small-cell lung cancer (CheckMate 032): a multicentre, open-label, phase 1/2 trial. Lancet Oncol 2016;17:883-895.

55. Tilden ME, Rosenbaum JT, Fraunfelder FT. Systemic sulfonamides as a cause of bilateral, anterior uveitis. Arch Ophthalmol 1991;109:67-69.

56. Akingbehin T, Villada JR. Metipranolol-associated granulomatous anterior uveitis. $\mathrm{Br} J$ Ophthalmol 1991;75:519-523.

57. Ostheimer TA, Burkholder BM, Leung T, Butler NJ, Dunn JP, Thorne JE. Tattoo-associated uveitis. Am J Ophthalmol 2014;158(3):637-643.

58. Rorsman H, Brehmer-Andersson E, Dahlquist I, Ehinger B, lacobsson S, Linell F, et al. Tattoo granuloma and uveitis. Lancet 1969;2:27-28. 